\title{
AATF mediates an antiapoptotic effect of the unfolded protein response through transcriptional regulation of AKT1
}

\author{
S Ishigaki ${ }^{*, 1}$, SG Fonseca ${ }^{1}$, CM Oslowski ${ }^{1}$, A Jurczyk ${ }^{2}$, JR Shearstone ${ }^{1}$, LJ Zhu ${ }^{1,3}$, MA Permutt $^{4}$, DL Greiner ${ }^{2,3}$, R Bortell ${ }^{2}$ \\ and $\mathrm{F}$ Urano*,1,3
}

Endoplasmic reticulum (ER) stress-mediated cell death has an important role in the pathogenesis of chronic diseases, including diabetes and neurodegeneration. Although proapoptotic programs activated by ER stress have been extensively studied, identification and characterization of antiapoptotic programs that counteract ER stress are currently incomplete. Through the gene expression profiling of $\beta$-cells lacking Wolfram syndrome 1 gene (WFS1), a causative gene for Wolfram syndrome, we discovered a novel antiapoptotic gene of the unfolded protein response (UPR), apoptosis antagonizing transcription factor (AATF). Here, we study the regulation of AATF, identify its target genes, and determine the basis for its antiapoptotic activities in response to ER stress. We show that AATF is induced by ER stress through the PERK-elF2 $\alpha$ pathway and transcriptionally activates the v-akt murine thymoma viral oncogene homolog 1 (AKT1) gene through signal transducer and activator of transcription 3 (Stat3), which sustains Akt1 activation and promotes cell survival. Ectopic expression of AATF or a constitutively active form of AKT1 confers on cells resistance to ER stress-mediated cell death, whereas RNAi-mediated knockdown of AATF or AKT1 renders cells sensitive to ER stress. We also discovered a positive crosstalk between the AATF and WFS1 signaling pathways. Thus, WFS1 deficiency or AATF deficiency mediates a self-perpetuating cycle of cell death. Our results reveal a novel antiapoptotic program relevant to the treatment of diseases caused by ER stress-mediated cell death.

Cell Death and Differentiation (2010) 17, 774-786; doi:10.1038/cdd.2009.175; published online 13 November 2009

The endoplasmic reticulum (ER) is an organelle responsible for several important cellular functions, including protein and lipid biosynthesis, $\mathrm{Ca}^{2+}$ storage, and signaling. Protein folding and processing enzymes, as well as the chemical environment within the $E R$, are required for proteins to properly fold into their functional conformation. Myriad pathological and physiological factors can perturb this unique protein-folding environment and disrupt ER homeostasis, causing an accumulation of unfolded proteins and ER stress. ${ }^{1}$ To attenuate ER stress and restore ER homeostasis, the unfolded protein response (UPR) is activated. There are three distinct responses of the UPR: upregulation of molecular chaperones to increase the ER-folding activity, translational attenuation to reduce ER workload, and induction of ERassociated protein degradation (ERAD) to promote clearance of unfolded and misfolded proteins. ${ }^{1,2}$ However, if the UPR fails to attenuate ER stress, the UPR directly activates proapoptotic programs. ${ }^{3,4}$ Some of the proposed mechanisms of ER stress-mediated cell death include the induction of the proapoptotic transcription factor $\mathrm{CHOP}$, the activation of the
C-Jun N-terminal kinase (JNK) pathway by IRE1, and the activation of BH-3-only proteins such as Puma or Bim. ${ }^{5-7}$ However, the identification and characterization of antiapoptotic programs in the UPR are currently incomplete. ${ }^{4}$

It has been suggested that ER stress-mediated cell death has an important role in the progression of diabetes, especially genetic forms of diabetes such as Wolfram syndrome..$^{8-11}$ Postmortem studies reveal a nonautoimmune-linked selective loss of pancreatic $\beta$-cells in patients with Wolfram syndrome. ${ }^{12}$ The causative gene for this syndrome was identified by two separate groups in 1998 and named Wolfram syndrome 1 gene (WFS1). ${ }^{13,14}$ We showed previously that WFS1 is a component of the UPR. WFS1 expression is induced transcriptionally in response to ER stress, and when suppressed, causes high levels of ER stress in $\beta$-cells, ${ }^{15}$ suggesting that $\beta$-cell death in Wolfram syndrome can be attributed to chronic, unresolvable ER stress due to a lack of functional WFS1 protein in $\beta$-cells. In this study, we report the identification of antiapoptotic programs of the UPR regulated by apoptosis antagonizing transcription factor (AATF) through

${ }^{1}$ Program in Gene Function and Expression, University of Massachusetts Medical School, Worcester, MA, USA; ${ }^{2}$ Division of Diabetes, University of Massachusetts Medical School, Worcester, MA, USA; ${ }^{3}$ Program in Molecular Medicine, University of Massachusetts Medical School, Worcester, MA, USA and ${ }^{4}$ Division of Endocrinology, Metabolism, and Lipid Research, Washington University School of Medicine, St. Louis, MO, USA

${ }^{*}$ Corresponding authors: S Ishigaki, Program in Gene Function and Expression, University of Massachusetts Medical School, 364 Plantation Street, Worcester, MA 01605-2324, USA. Tel: 508856 4356; Fax: 508856 4650; E-mail: Shinsuke.Ishigaki@ umassmed.edu; ishigaki-ns@ umin.ac.jp

or F Urano, Tel: 508856 6012; Fax: 508856 4650; E-mail: Fumihiko.Urano@umassmed.edu; urano@erstress.com

Keywords: apoptosis; diabetes; endoplasmic reticulum stress; neurodegeneration; unfolded protein response

Abbreviations: ER stress, endoplasmic reticulum stress; UPR, unfolded protein response; AATF, apoptosis antagonizing transcription factor; WFS1, Wolfram syndrome 1 gene; AKT1, v-akt murine thymoma viral oncogene homolog 1; STAT3, signal transducer and activator of transcription 3; JNK, c-Jun N-terminal kinase; ERAD, endoplasmic reticulum-associated protein degradation

Received 21.8.09; revised 02.10.09; accepted 07.10.09; Edited by S Kumar; published online 13.11.09 
the gene expression profiling of $\beta$-cells lacking WFS1 and demonstrate how AATF confers resistance to ER stressmediated cell death.

\section{Results}

Gene expression profiling of $\beta$-cells lacking WFS 1 identifies a novel antiapoptotic factor of the UPR. Several considerations raised the possibility that antiapoptotic genes of the UPR might be transcriptionally downregulated in $\beta$-cells lacking WFS1. Previous studies have shown that WFS1-deficient $\beta$-cells are under chronic ER stress conditions and are sensitive to ER stress-mediated cell death. ${ }^{10,11}$ We have found that WFS1-knockdown $\beta$-cells are under chronic ER stress conditions. ${ }^{15}$ To confirm that knockdown of WFS1 in $\beta$-cells leads to ER stress-mediated cell death, INS-1 832/13 cells were transfected with small interfering RNA (siRNA) directed against WFS1 and then challenged with an ER stress inducer, thapsigargin. Apoptosis was measured by caspase-3 cleavage and TUNEL staining. Consistent with previous findings, WFS1-knockdown $\beta$-cells were sensitive to ER stress-mediated cell death (Figure 1a and b).

To examine the possible role of WFS1 in the activation of antiapoptotic pathways, we first systematically identified genes that were differentially expressed in WFS1-knockdown INS-1 832/13 cells. Among the 298 genes differentially expressed $(P<0.01)$, transcriptionally downregulated genes were chosen as candidates for conferring resistance to ER stress-mediated cell death. These candidate genes were prioritized, first on the magnitude of transcriptional downregulation and second, on the basis of a known role in apoptosis. Twelve genes were decreased by more than twofold (Supplementary Table 1). Among these, we focused on AATF, which was significantly suppressed by WFS1knockdown ( $\log 2$ ratio $=-1.23$ ) and was reported to have a role in apoptosis. ${ }^{16-18}$

We verified that AATF expression was downstream of WFS1. AATF mRNA and protein expressions were downregulated in WFS1-knockdown INS-1 832/13 cells as compared with control cells, both under ER stress conditions (Figure 1c and d) and normal conditions (data not shown). Furthermore, we found that AATF is highly expressed in mouse islets (Supplementary Figure 1A), whereas in WFS1knockout mouse islets, AATF protein expression was markedly decreased as compared with control littermates (Figure 1e).

AATF is a component of the UPR. We next sought to determine whether AATF could be a component of the UPR. We measured the expression levels of AATF mRNA in INS-1 832/13 cells, neuro2A cells, and mouse embryonic fibroblasts treated with various ER stress inducers. We found that AATF mRNA was upregulated by ER stress inducers, including tunicamycin, thapsigargin, and MG132, but not by a general apoptosis inducer, staurosporin, indicating that AATF expression is specifically increased by ER stress (Figure 2a). We confirmed the upregulation of AATF by ER stress using both cytoplasmic and nuclear protein extracts from INS-1 832/13 cells (Figure 2b). After treating these cells with thapsigargin, we compared the upregulation of AATF mRNA by ER stress to other ER stress markers, including BiP, Chop, XBP-1, and WFS1. We found that AATF mRNA expression continued to increase up to $24 \mathrm{~h}$ after the initiation of ER stress (Figure 2c).

AATF expression is regulated by PERK-mediated elF2 $\alpha$ phosphorylation. We next investigated the pathway by which AATF expression could be regulated. We measured the expression levels of AATF by real-time PCR in Ire $1 \alpha^{-1-}$ and Perk $^{-1-}$ mouse embryonic fibroblasts under ER stress conditions. IRE $1 \alpha$ and PERK are ER-resident protein kinases and master regulators of the UPR. In wild-type fibroblasts, expression levels of AATF mRNA were increased two- to threefold by tunicamycin and thapsigargin, whereas the induction of AATF was attenuated in Perk ${ }^{-1}$ mouse embryonic fibroblasts, but not in Ire $1 \alpha^{-1-}$ cells (Figure 3a and $b$ ). We also tested the involvement of ATF6, another upstream component of the UPR, in AATF expression, using an siRNA approach. AATF induction was attenuated in Perk-knockdown cells (Supplementary Figure 2A), but not in ATF6-knockdown cells (Supplementary Figure 2B). To confirm the role of PERK in AATF expression, we transfected Perk $^{-1-}$ mouse embryonic fibroblasts with a PERK expression plasmid, then measured AATF gene expression. We also measured Chop expression as a control. PERK expression could restore both AATF and Chop expression (Supplementary Figure $2 \mathrm{C}$ ). These results indicate that PERK signaling regulates AATF expression.

It is well established that PERK-mediated elF2 $\alpha$ phosphorylation is important in the upregulation of its target genes. ${ }^{19,20}$ We were therefore interested in determining whether elF2 $\alpha$ phosphorylation could increase AATF expression. We treated wild-type and Perk $^{-1-}$ mouse fibroblasts with salubrinal, a compound that increases elF2 $\alpha$ phosphorylation, ${ }^{21}$ and then measured AATF expression. We also measured Chop expression as a control. As expected, AATF and Chop expressions were increased by salubrinal treatment in both wild-type and Perk $^{-1-}$ mouse embryonic fibroblasts (Figure 3c).

AATF protects cells from ER stress-mediated apoptosis. We next examined the ability of AATF to protect cells from ER stress-mediated apoptosis. We transfected INS-1 832/13 cells with siRNA directed against AATF, then challenged the cells with thapsigargin or staurosporin and measured the cleavage of caspase-3. As compared with control cells, cells transfected with siRNA directed against AATF showed increased cleavage of caspase- 3 by thapsigargin (Figure $4 a$, center panel), but not staurosporin (Figure 4a, right panel), demonstrating that inactivation of AATF rendered cells specifically sensitive to ER stress-mediated apoptosis. To confirm this, we measured apoptosis in AATF-knockdown cells using TUNEL staining. Figure $4 \mathrm{~b}$ shows that AATF suppression increased the number of TUNEL-positive cells in the presence of ER stress. We next sought to determine whether AATF overexpression would render INS-1 832/13 cells resistant to ER stressmediated apoptosis. As expected, AATF induction using a doxycycline-induced expression system decreased caspase-3 


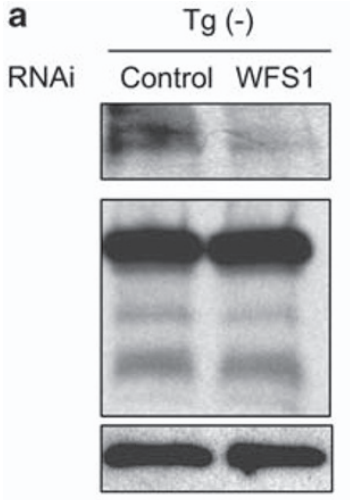

IB: anti-WFS1
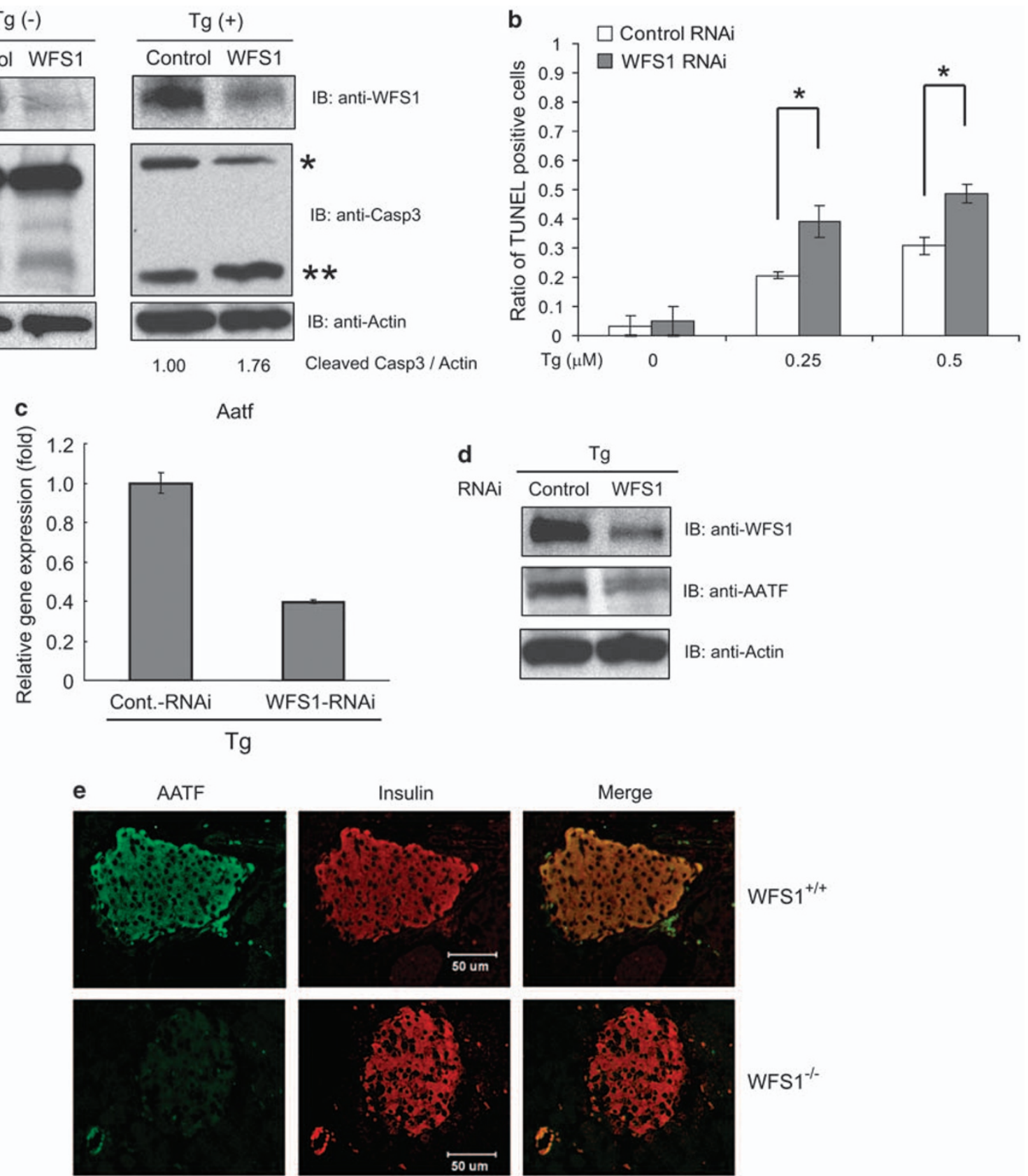

d
RNAi

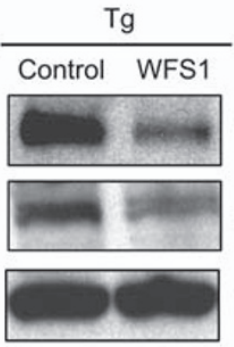

IB: anti-WFS1

IB: anti-AATF

IB: anti-Actin
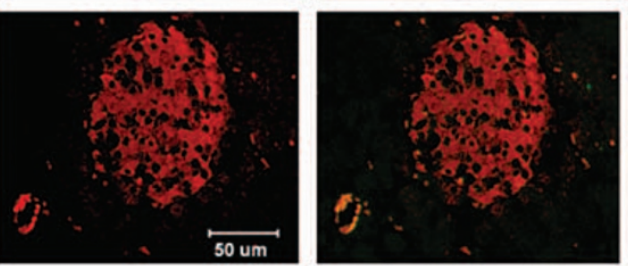

$\mathrm{WFS}^{-1-}$

Figure 1 AATF is downregulated in WFS1-deficient $\beta$-cells that are susceptible to ER stress-mediated apoptosis. (a) INS-1 832/13 cells were transfected with control scrambled siRNA or siRNA directed against WFS1, then treated with or without thapsigargin (Tg, $0.5 \mu \mathrm{M})$ for $16 \mathrm{~h}$. Expression levels of caspase-3 (Casp3), WFS1, and actin were measured by immunoblot. Single and double asterisks indicate uncleaved and cleaved caspase-3, respectively. The ratio between cleaved caspase-3 and actin was measured using ImageJ software. (b) INS-1 832/13 cells were transfected with control scrambled siRNA or siRNA directed against WFS1, then treated with three different concentrations $(0,0.25$, and $0.5 \mu \mathrm{M})$ of thapsigargin (Tg) for $24 \mathrm{~h}$. Apoptotic cells were detected by TUNEL staining $(n=3$; values are mean \pm S.D.). Statistics were performed by two-way ANOVA. * $P<0.01$ denotes significant differences between cells transfected with control scrambled siRNA and siRNA directed against WFS1. (c) INS-1 832/13 cells were transfected with control scrambled siRNA or siRNA directed against WFS1, then treated with thapsigargin $(\mathrm{Tg}, 1 \mu \mathrm{M})$ for $8 \mathrm{~h}$. Expression levels of Aatf were measured by real-time-PCR $(n=3$; values are mean \pm S.D.). (d) Expression levels of AATF, WFS1, and actin proteins were measured by immunoblot on the same samples as in panel c. (e) WFS1 ${ }^{-1-}$ and wild-type littermate mouse pancreata were analyzed by immunohistochemistry using anti-AATF and anti-insulin antibodies. Merged image shows the colocalization of AATF and insulin

cleavage by thapsigargin (Figure 4c, upper panel). To confirm this, we measured apoptosis in these cells using TUNEL staining. Figure 4c (lower panel) shows that AATF induction decreased the number of TUNEL-positive cells.
We next sought to verify whether AATF had a function in protecting cells from ER stress-mediated apoptosis using a more physiological ER stress inducer, glucose deprivation. ${ }^{22}$ We predicted that glucose deprivation could cause ER stress 


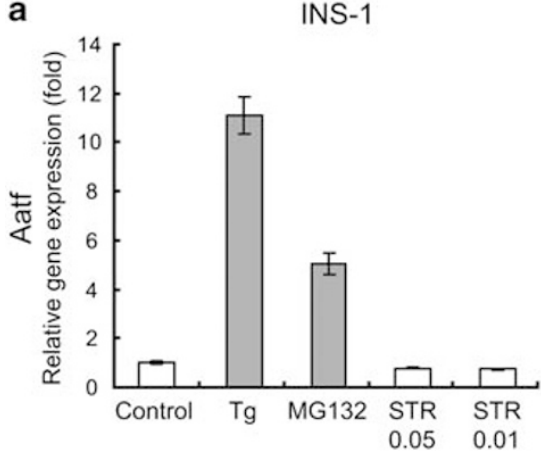

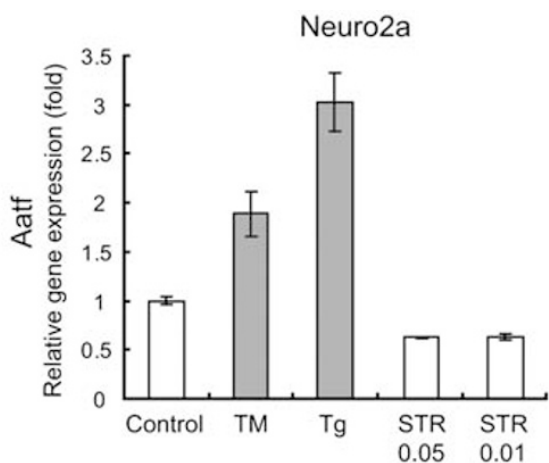
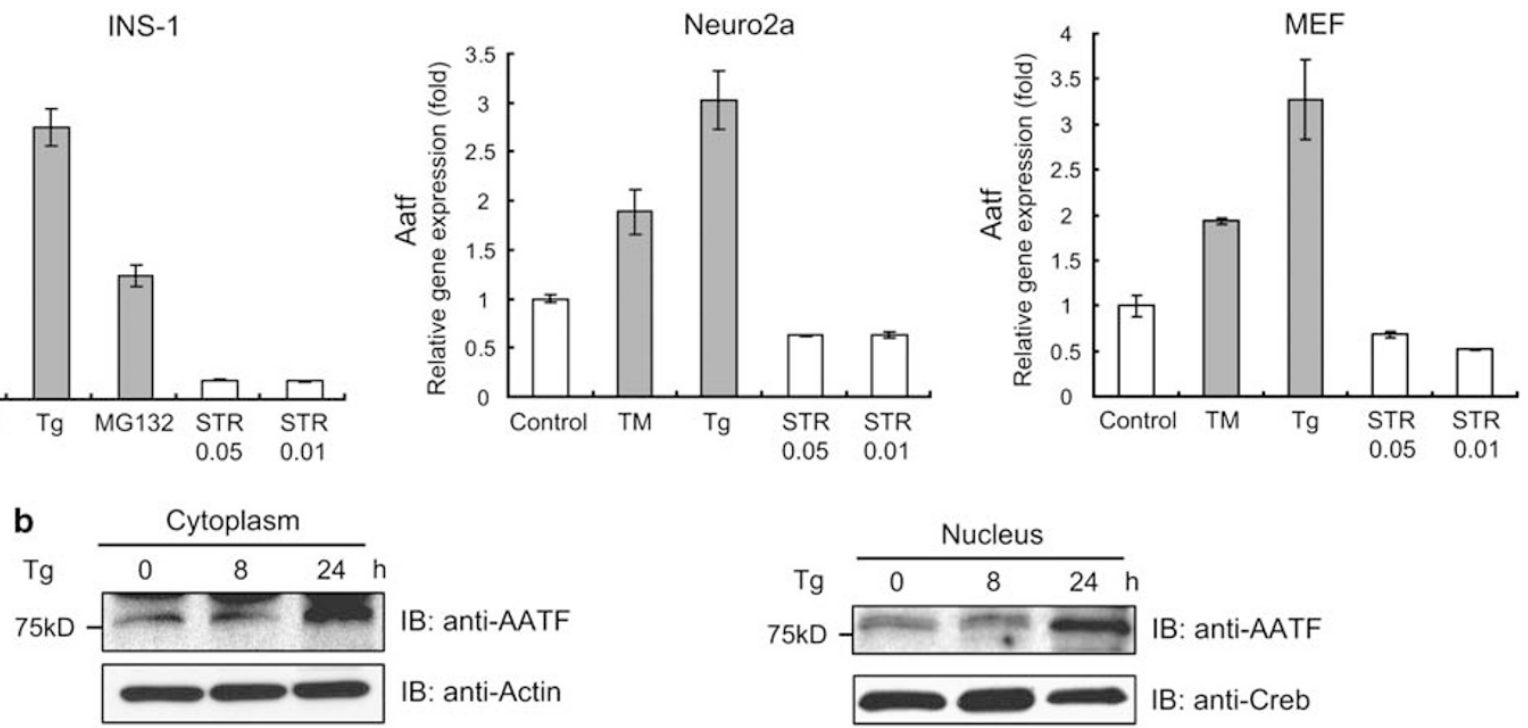

C

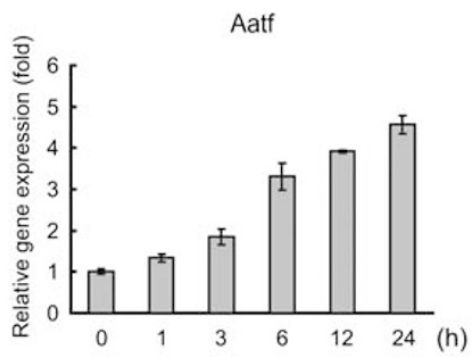

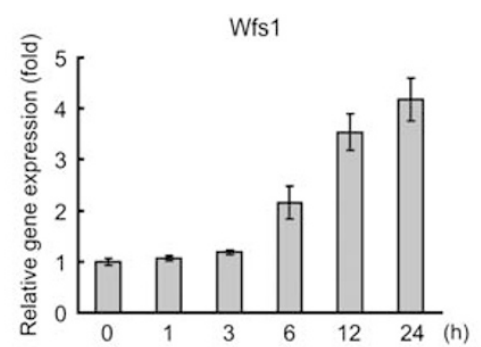

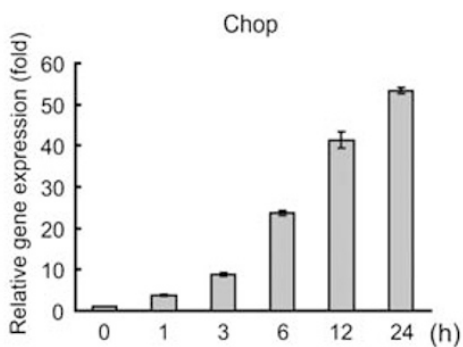

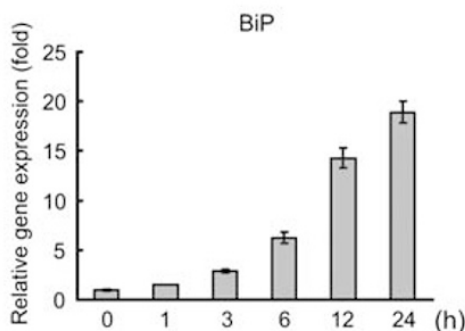

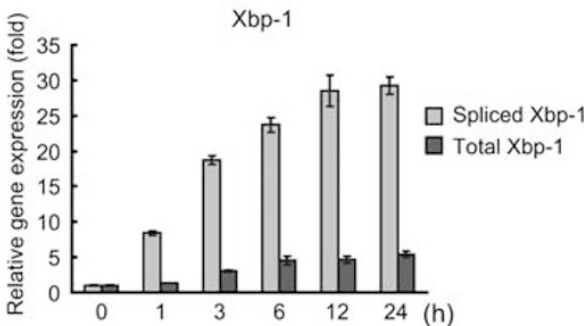

Figure 2 AATF is induced by ER stress. (a) INS-1 832/13 cells, neuro2a cells, and mouse embryonic fibroblasts were treated with thapsigargin (Tg, $1 \mu \mathrm{M})$, MG132 $(2 \mu \mathrm{M})$, tunicamycin (TM, $5 \mu \mathrm{g} / \mathrm{ml}$ ), or staurosporin (STR, 0.05 and $0.01 \mu \mathrm{M})$ for $16 \mathrm{~h}$ or untreated. Expression levels of Aatf were measured by real-time PCR $(n=3$; values are mean \pm S.D.). (b) INS-1 832/13 cells were treated with thapsigargin $(\mathrm{Tg}, 1 \mu \mathrm{M})$ for the indicated times (lower panel). Expression levels of Aatf and Creb were measured by immunoblot using cytoplasmic and nuclear extracts. (c) INS-1 832/13 cells were treated with thapsigargin (Tg, $0.5 \mu \mathrm{M})$ for the indicated times. Expression levels of Aatf, Wfs1, Chop, BiP, and total and spliced Xbp-1 mRNA were measured by real-time-PCR $(n=3$; values are mean \pm S.D. $)$

and AATF upregulation. To confirm this idea, we cultured INS-1 832/13 cells in glucose-free media, then measured expression levels of Chop and AATF, as well as capase-3 cleavage. We found that glucose deprivation increased Chop and AATF expression, as well as caspase-3 cleavage, indicating that glucose deprivation induces ER stressmediated apoptosis (Supplementary Figure 3). We then challenged AATF-knockdown INS-1 832/13 cells with glucose deprivation. AATF-knockdown sensitized INS-1 832/13 cells to glucose deprivation-mediated apoptosis (Figure 4d). Conversely, ectopic expression of AATF using doxycycline-mediated induction decreased caspase-3 cleavage by glucose deprivation (Figure 4e).
To determine whether AATF overexpression could rescue cells from apoptosis caused by the suppression of WFS1, we transfected AATF-inducible INS-1 832/13 cells with control scrambled siRNA or siRNA directed against WFS1. We then challenged these cells by thapsigargin treatment with or without the induction of AATF, and measured caspase-3 cleavage. Figure $4 \mathrm{f}$ shows that AATF induction could rescue ER stress-mediated apoptosis caused by the suppression of WFS1. Collectively, these results indicate that AATF functions in protecting cells from ER stress-mediated apoptosis.

Akt1 is a downstream target of AATF. Apoptosis antagonizing transcription factor has an L-zip domain in the 


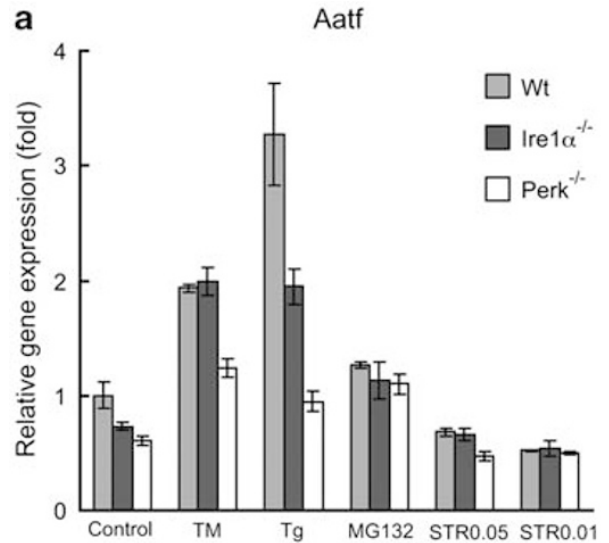

C

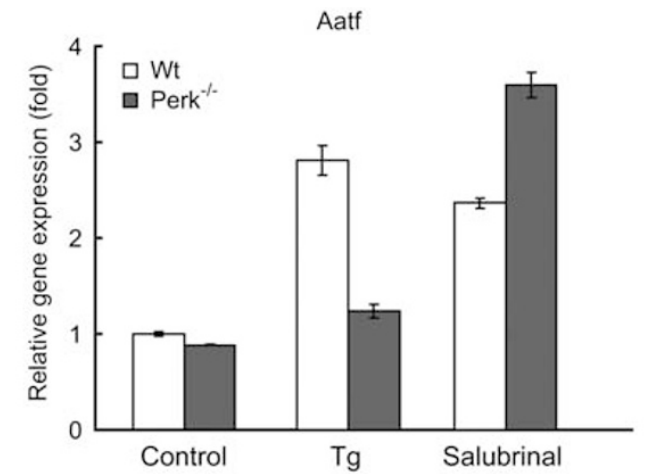

b

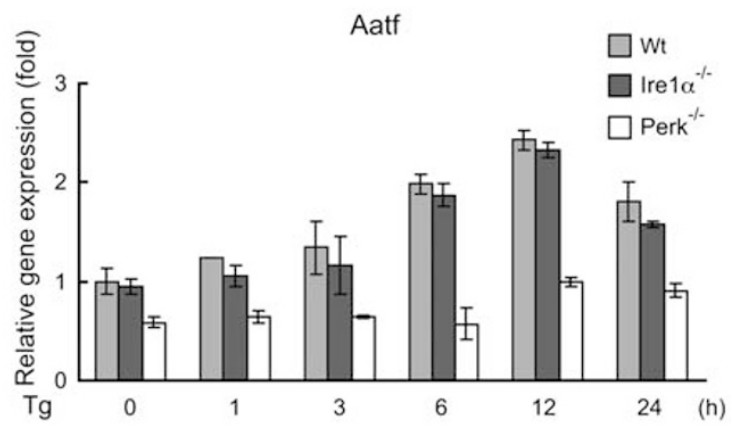

Chop
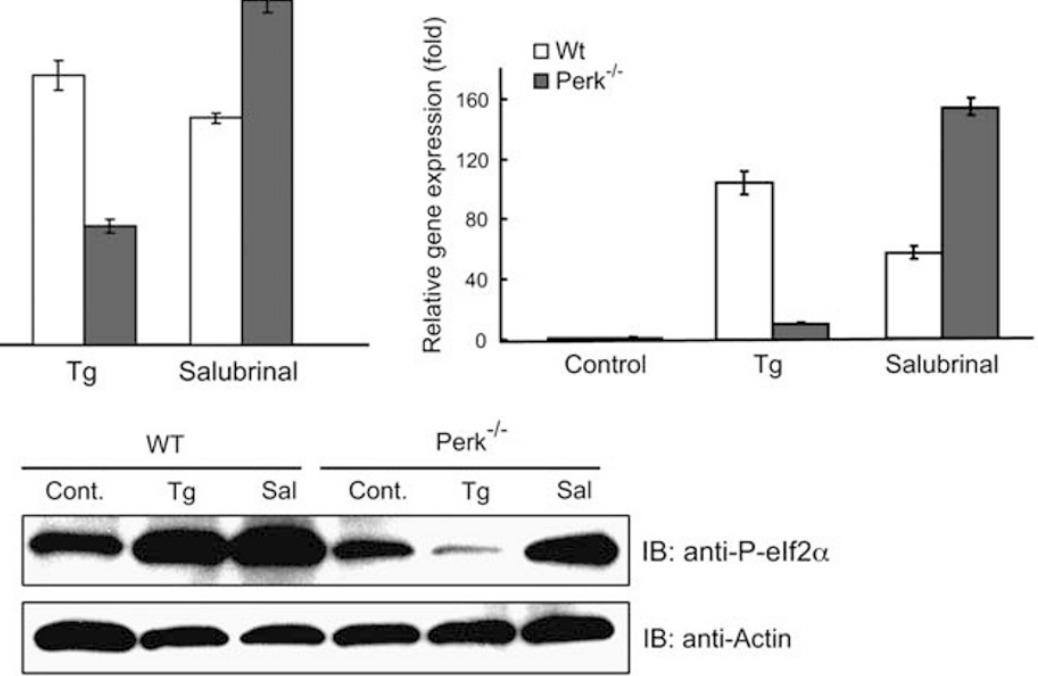

Figure 3 AATF expression is regulated by PERK-mediated elF2 $\alpha$ phosphorylation. (a) Wild-type (Wt), Ire $1 \alpha^{-/-}$, and Perk ${ }^{-1-}$ mouse embryonic fibroblasts were treated with tunicamycin (TM, $5 \mu \mathrm{g} / \mathrm{ml})$, thapsigargin $(\mathrm{Tg}, 1 \mu \mathrm{M})$, or staurosporin (STR, 0.05 and $0.01 \mu \mathrm{M})$ for $16 \mathrm{~h}$ or untreated. Expression levels of Aatf were measured by real-time $\operatorname{PCR}\left(n=3\right.$; values are mean \pm S.D.). (b) Wild-type (Wt), Ire $1 \alpha^{-1-}$, and Perk ${ }^{-l-}$ mouse embryonic fibroblasts were treated with thapsigargin $(\mathrm{Tg}, 1 \mu \mathrm{M})$ at different times. Expression levels of Aatf were measured by real-time PCR $\left(n=3\right.$; values are mean \pm S.D.). (c) Wild-type (Wt) and Perk ${ }^{-1-}$ mouse embryonic fibroblasts were treated with thapsigargin (Tg, $1 \mu \mathrm{M}$ ) or Salubrinal (Sal, $75 \mathrm{nM}$ ) for $16 \mathrm{~h}$. Expression levels of Aatf (left panel) and Chop (right panel) were measured by real-time PCR ( $n=3$; values are mean \pm S.D.). Expression levels of phosphorylated elf $2 \alpha$ and actin were measured by immunoblot

$\mathrm{N}$-terminal, followed by two nuclear localization signals in the C-terminal, and has been proposed to function in transcriptional regulation. ${ }^{16,18}$ Indeed, AATF was mainly localized to the nucleus and the nucleolus in the cell (Supplementary Figure 4). To identify the transcriptional targets of AATF, we compared gene expression profiles of AATF-knockdown INS-1 832/13 cells and INS-1 832/13 cells transfected with scrambled siRNA, after treatment with thapsigargin for $8 \mathrm{~h}$. Genes that were significantly downregulated $(P<0.01)$ more than twofold by AATF siRNA were defined as potential AATF targets under ER stress conditions. Seven target genes were identified (Supplementary Table 2). One of the target genes identified was the serine/threonine kinase, Akt1, which is well known for its role in promoting cell survival under various conditions. ${ }^{23,24}$

We confirmed that AATF knockdown by siRNA suppressed Akt1 mRNA and protein expression (Figure 5a). We also confirmed that AATF knockdown decreased mRNA expression levels of the other six target genes (Supplementary Figure 5A). We next asked whether Akt1 expression was increased by ER stress. We measured the expression levels of Akt1 mRNA in the presence of ER stress in INS-1 832/13, neuro2A, and mouse embryonic fibroblasts. Figure $5 b$ shows that Akt1 mRNA expression was increased 1.5- to 2-fold by various ER stress inducers, including tunicamycin, thapsigargin, and MG132, but not staurosporin. By measuring Akt1 mRNA expression at different times under ER stress conditions, we found that Akt1 expression was increased during ER stress, with a peak at $24 \mathrm{~h}$ (Figure 5c, left panel). Collectively, these results indicate that Akt1 is a target for AATF in the presence of ER stress.

It has been proposed that phosphorylation of Akt is important in protecting $\beta$-cells from apoptosis. ${ }^{25}$ We were therefore interested in measuring the phosphorylation levels of Akt at 

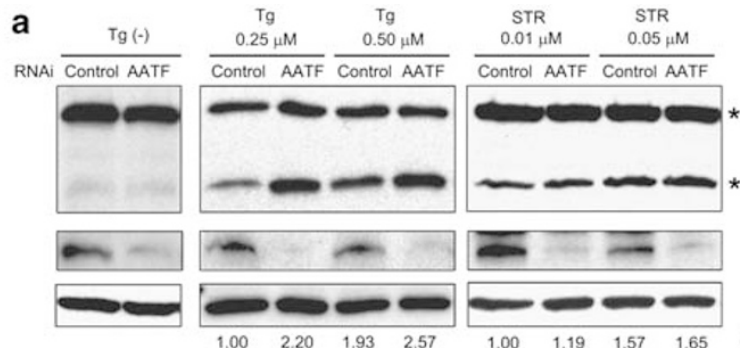

IB: anti-Casp3

**

IB: anti-AATF

IB: anti-Actin

Cleaved Casp $3 /$ Actin
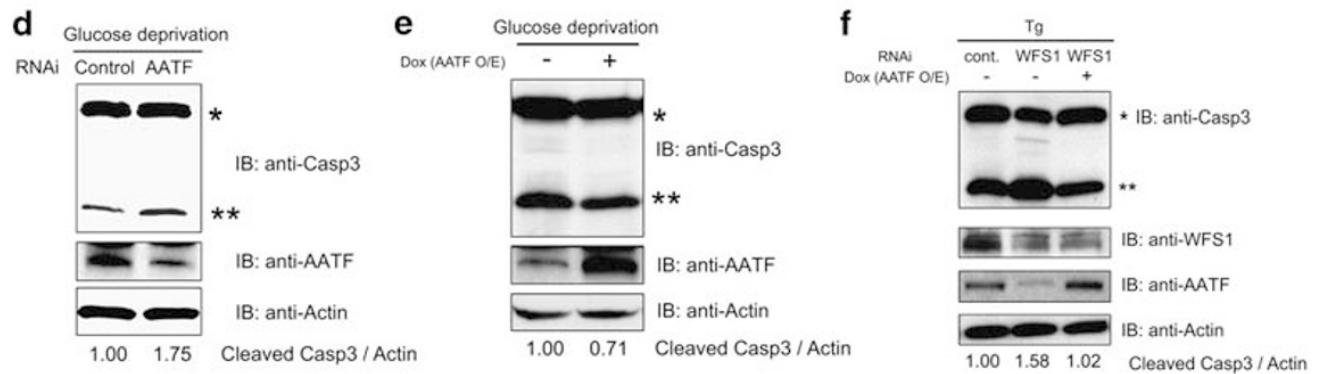
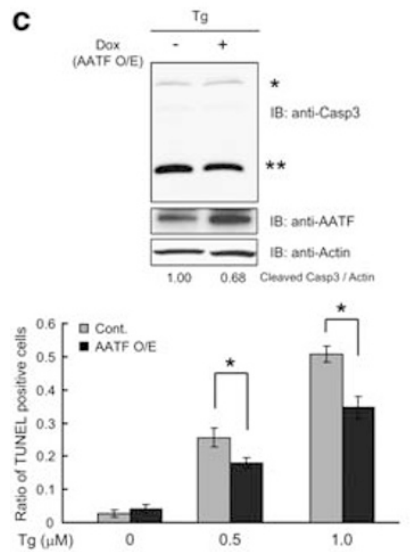

Figure 4 AATF is an antiapoptotic component of ER stress signaling. (a) INS-1 832/13 cells were transfected with control scrambled siRNA or siRNA directed against AATF, then treated with or without thapsigargin $(\mathrm{Tg}, 0.25 \mu \mathrm{M}$ and $0.5 \mu \mathrm{M})$ or staurosporin (STR) for $16 \mathrm{~h}$. Expression levels of caspase-3 (Casp3), AATF, and actin were measured by immunoblot. Single and double asterisks indicate uncleaved and cleaved caspase-3, respectively. The ratio between cleaved caspase-3 and actin was measured using ImageJ software. (b) INS-1 832/13 cells were transfected with control scrambled siRNA or siRNA directed against AATF, then treated with three different concentrations $(0,0.25$, and $0.5 \mu \mathrm{M})$ of thapsigargin $(\mathrm{Tg})$ for $24 \mathrm{~h}$. Apoptotic cells were detected by TUNEL staining $(n=3$; values are mean \pm S.D.). Statistics were performed by two-way ANOVA. ${ }^{*} P<0.01$ denotes significant differences between cells transfected with control scrambled siRNA and siRNA directed against AATF. (c) INS-1 832/13 cells were stably transduced with LV-TO/AATF, an inducible lentivirus expressing AATF. Cells were cultured with doxycycline $(2 \mu \mathrm{g} / \mathrm{ml})$ to induce AATF or without doxycycline for $48 \mathrm{~h}$, then challenged with thapsigargin ( $\mathrm{Tg}, 0.5 \mu \mathrm{M})$ for $16 \mathrm{~h}$. Expression levels of caspase-3 (Casp3), AATF, and actin were measured by immunoblot. Single and double asterisks indicate uncleaved and cleaved caspase-3, respectively. The ratio between cleaved caspase-3 and actin was measured using ImageJ software (upper panel). Cells were cultured with doxycycline $(2 \mu \mathrm{g} / \mathrm{ml})$ to induce AATF (AATF O/E) or without doxycycline (Cont) for $48 \mathrm{~h}$, then challenged with three different concentrations of thapsigargin (0, 0.5 , and $1.0 \mu \mathrm{M})$ for $24 \mathrm{~h}$. Apoptotic cell death was assessed by the TUNEL assay $\left(n=3\right.$; values are mean \pm S.D.) Statistics were performed by two-way ANOVA. ${ }^{*} P<0.01$ denotes significant differences between cells with and without doxycycline (lower panel). (d) INS-1 832/13 cells were transfected with control scrambled siRNA (Control) or siRNA directed against AATF, then cultured in glucose-free media for $48 \mathrm{~h}$. Expression levels of caspase-3 (Casp3), AATF, and actin were measured by immunoblot. Single and double asterisks indicate uncleaved and cleaved caspase-3, respectively. The ratio between cleaved caspase-3 and actin was measured using ImageJ software. (e) INS-1 $832 / 13$ cells were stably transduced with LV-TO/AATF, an inducible lentivirus expressing AATF. Cells were cultured with doxycycline $(2 \mu \mathrm{g} / \mathrm{ml})$ to induce AATF or without doxycycline $(2 \mu \mathrm{g} / \mathrm{ml})$ for $48 \mathrm{~h}$, then cultured in glucose-free media for $48 \mathrm{~h}$. Expression levels of caspase-3 (Casp3), AATF, and actin were measured by immunoblot. Single and double asterisks indicate uncleaved and cleaved caspase-3, respectively. The ratio between cleaved caspase-3 and actin was measured using ImageJ software. (f) INS-1 $832 / 13$ cells were stably transduced with LV-TO/AATF, an inducible lentivirus expressing mouse AATF. Cells were cultured with doxycycline $(2 \mu \mathrm{g} / \mathrm{ml})$ to induce AATF or without doxycyclin for $48 \mathrm{~h}$, then challenged with thapsigargin $(\mathrm{Tg}, 0.5 \mu \mathrm{M})$ for $16 \mathrm{~h}$. Cells were also transfected with control, scrambled siRNA (Cont), or siRNA against WFS1. Expression levels of caspase-3 (Casp3), AATF, WFS1, and actin were measured by immunoblot. Single and double asterisks indicate uncleaved and cleaved caspase-3, respectively. The ratio between cleaved caspase-3 and actin was measured using ImageJ software

different times after thapsigargin treatment. We found that the phosphorylation level of Akt was increased up to $8 \mathrm{~h}$ after treatment, but decreased at $24 \mathrm{~h}$ (Figure $5 \mathrm{c}$, right panel), as seen in previous reports. ${ }^{25,26}$ To study the relationship between AATF suppression and Akt phosphorylation, we suppressed AATF expression using siRNA directed against AATF in INS-1 832/13 cells, treated the cells with thapsigargin for 0,3 , and $8 \mathrm{~h}$, then measured Akt expression and Akt phosphorylation levels by immunoblot. Both Akt expression and Akt phosphorylation levels were decreased by AATF siRNA (Figure 5d). To further confirm the relationship between AATF and Akt1 expression, we generated an inducible lentivirus system expressing the AATF gene. We infected INS-1 832/13 cells with the virus and measured Akt1 expression levels, finding that AATF overexpression enhanced Akt1 mRNA expression under ER stress conditions, leading to an increase in Akt phosphorylation (Figure 5e).

Regulation of Akt1 expression through the AATF-Stat3 complex. Signal transducer and activator of transcription 3 (Stat3) has been proposed to have an important role in Akt1 expression, ${ }^{27,28}$ raising the possibility that Stat3 is involved in AATF-mediated induction of Akt1. A plasmid expressing constitutively active Stat3 with or without AATF was cotransfected into neuro2A cells, along with a reporter plasmid containing $1.3 \mathrm{~kb}$ of the Akt1 promoter driving the luciferase gene, which showed the highest induction of Akt1 promoter activity by Stat3 among the promoter fragments with different lengths (Supplementary Figure 6). Stat3 expression caused a 1.4-fold induction of luciferase activity (Figure 6a, lane 4), 

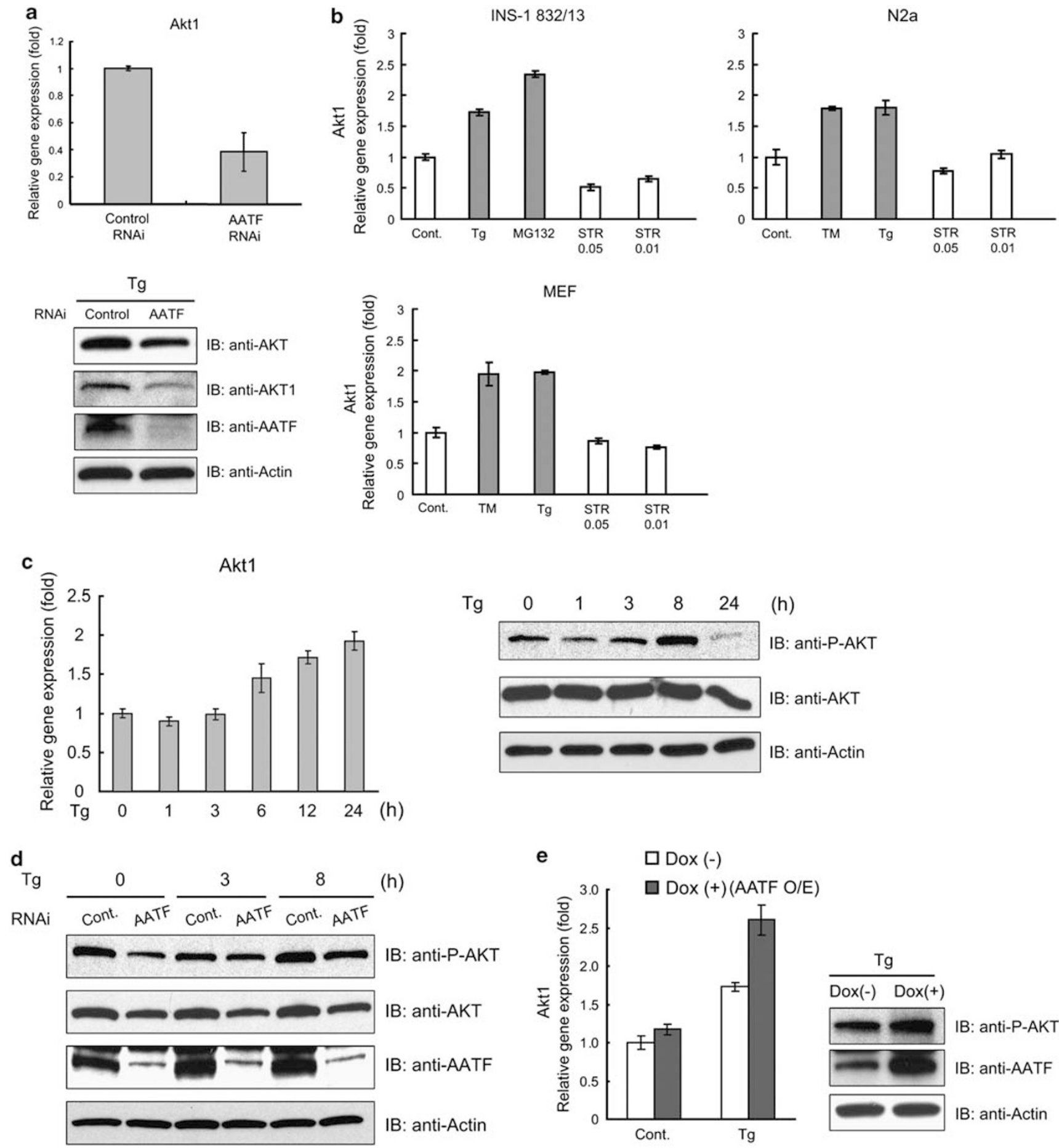

(h)

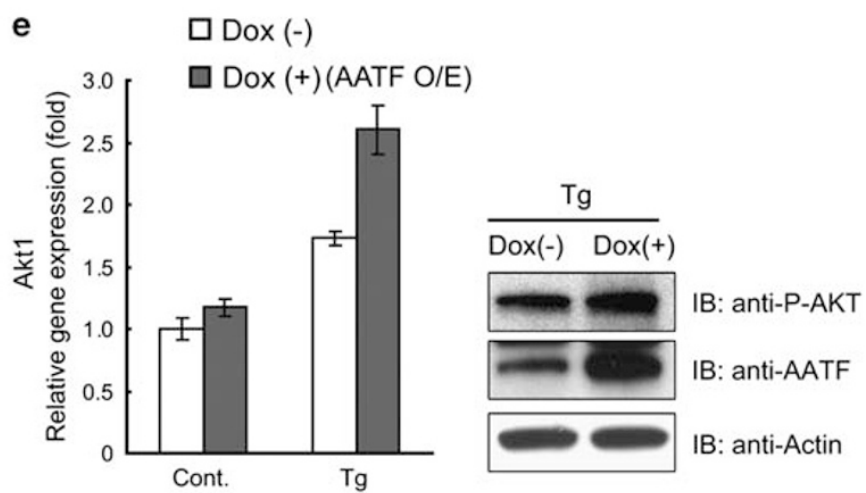

Figure 5 Akt1 is a downstream target of AATF. (a) INS-1 832/13 cells were transfected with scrambled siRNA (control) or siRNA directed against AATF, and then challenged with thapsigargin $(\mathrm{Tg}, 1 \mu \mathrm{M})$ for $8 \mathrm{~h}$. Expression levels of Akt1 mRNA were measured by real-time PCR $(n=3$; values are mean \pm S.D.) (upper panel). Expression levels of total AKT (AKT), AKT1, AATF, and actin were measured by immunoblot (lower panel). (b) INS-1 832/13 cells, neuro2a (N2a) cells, and mouse embryonic fibroblasts (MEF) were treated with thapsigargin (Tg, $1 \mu \mathrm{M})$, MG132 $(2 \mu \mathrm{M})$, tunicamycin (TM, $5 \mu \mathrm{g} / \mathrm{ml})$, or staurosporin (STR, $0.05 \mu \mathrm{M}$ and $0.01 \mu \mathrm{M})$ for $16 \mathrm{~h}$ or untreated. Expression levels of Akt1 were measured by real-time PCR $(n=3$; values are mean \pm S.D.) (c) INS-1 832/13 cells were treated with thapsigargin $(\mathrm{Tg}, 1 \mu \mathrm{M})$ for the indicated times. Expression levels of Akt1 mRNA were measured by real-time-PCR $(n=3$; values are mean \pm S.D.) (left panel). Expression levels of phosphorylated AKT (P-AKT), total AKT (AKT), and actin were also measured by immunoblot (right panel). (d) INS-1 832/13 cells were transfected with scramble siRNA (control) or siRNA directed against AATF, then treated with thapsigargin $(\mathrm{Tg})(0.5 \mu \mathrm{M})$ for the indicated times. Expression levels of phosphorylated AKT (P-AKT), total AKT (AKT), AATF, and actin were measured by immunoblot. (e) INS-1 832/13 cells were stably transduced with LV-TO/AATF, an inducible lentivirus expressing AATF. Cells were cultured with or without doxycycline (Dox, $2 \mu \mathrm{g} / \mathrm{ml})$ to induce AATF for $48 \mathrm{~h}$, then challenged with thapsigargin $(\mathrm{Tg}, 0.5 \mu \mathrm{M})$ for $16 \mathrm{~h}$. Expression levels of Akt1 mRNA were measured by real-time PCR $(n=3 ;$ values are mean \pm S.D.) (left panel). Expression levels of phosphorylated AKT (P-AKT), AATF, and actin were also measured by immunoblot (right panel) 


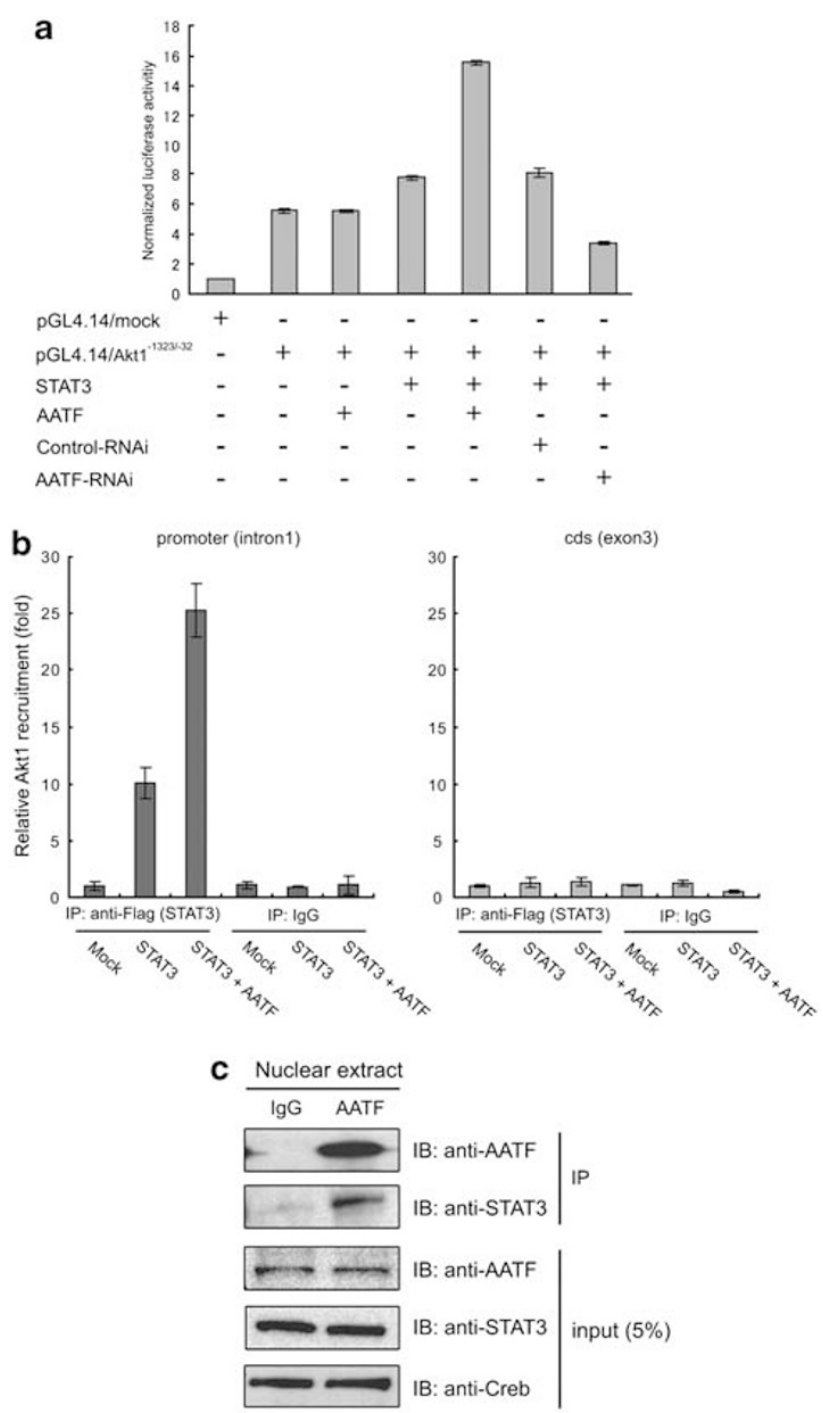

Figure 6 Regulation of Akt1 expression through the AATF-Stat3 complex. (a) Luciferase activity in neuro2a cells transfected with AKT1 (pGL4.14/ Akt $1^{-1323 /-1}$ ) or control promoter constructs, plus vectors expressing the indicated proteins or siRNA directed against AATF $(n=3$; values are mean \pm S.D.). (b) Quantified ChIP analysis using real-time PCR was performed. Relative recruitment was defined as the ratio of amplification of the PCR product relative to $1 \%$ of input genomic DNA. Value obtained from mock was defined as $1(n=3$; values are mean \pm S.D.). (c) Nuclear fractions of HEK293T cells were extracted and applied for immunoprecipitation using an anti-AATF antibody. Immunoprecipitated samples and $5 \%$ inputs were blotted with indicated antibodies

and siRNA-mediated knockdown of AATF abrogated this induction (Figure 6a, lane 7). The addition of AATF to Stat3 led to a 2.8-fold induction of luciferase activity (Figure 6a, lane 5). Chromatin immunoprecipitation (ChIP) analysis verified that Stat3 binding to the Akt1 promoter was enhanced in response to AATF expression (Figure 6b). The data of Figure $6 a$ and $b$ predict that Stat3 and AATF should interact in the nucleus. Consistent with this prediction, Figure $6 \mathrm{c}$ shows that Stat3 and AATF interact in the nucleus.

The AATF-AKT1 pathway protects cells from ER stressmediated apoptosis. To study the involvement of the
AATF-AKT1 pathway in protecting cells from ER stressmediated apoptosis, we suppressed the v-akt murine thymoma viral oncogene homolog 1 (AKT1) pathway in INS-1 832/13 cells using siRNA directed against Akt1 (Figure 7a, left panel) or an Akt inhibitor, SH-5 (Figure 7a, right panel). We then challenged these cells with thapsigargin and measured the cleavage of caspase-3. Both Akt1 siRNA and the Akt inhibitor increased cleavage of caspase-3, indicating that Akt1 gene expression and its phosphorylation have a role in protecting cells from ER stress-mediated apoptosis (Figure 7a). We also suppressed the expression of the other six target genes in INS-1 832/13 cells, using siRNAs directed against them (Supplementary Figure 7A), then challenged these cells with thapsigargin and measured the cleavage of caspase-3 (Supplementary Figure 7B). Only the suppression of Akt1 had a significant effect on apoptosis in cells challenged with thapsigargin. To study the involvement of the Akt1 pathway in protecting cells from apoptosis mediated by glucose deprivation, we blocked the Akt1 pathway in INS-1 832/13 cells using an Akt inhibitor, $\mathrm{SH}-5$, then challenged the cells with glucose deprivation and measured the cleavage of caspase-3. Akt1 inhibitor treatment increased the cleavage of caspase-3 (Figure 7b). To determine whether Akt1 overexpression can rescue cells from apoptosis caused by the suppression of AATF, we transfected INS-1 832/13 cells with control siRNA or siRNA against AATF. We then challenged these cells with or without the induction of Akt1, using the lentivirus-based doxycyclinemediated Akt1 induction system, and measured caspase-3 cleavage. Figure 7c shows that Akt1 induction could rescue ER stress-mediated apoptosis caused by the suppression of AATF. To further confirm the role of Akt1 in protecting cells from ER stress-mediated apoptosis, we suppressed Akt1 gene expression by RNAi in INS-1 832/13 cells ectopically expressing AATF and measured caspase-3 cleavage. As expected, RNAi-mediated knockdown of Akt1 nullified the antiapoptotic effect of AATF and made the cells sensitive to ER stress-mediated apoptosis (Figure 7d).

To confirm and extend these observations, we tested whether ectopic expression of AATF and Akt1 could protect primary mouse islets from ER stress-mediated apoptosis. We derived lentivirus-expressing AATF, a constitutively active form of Akt1, and GFP as a control, transduced primary islets with the virus, and challenged them with thapsigargin. We confirmed an efficient transduction of primary islets by monitoring GFP expression and measuring AATF and Akt1 mRNA expression levels (Supplementary Figure 8A and B). Apoptosis was analyzed by TUNEL staining. Ectopic expression of AATF and Akt1 protected primary islets from ER stress-mediated cell death (Figure 7e). This result was confirmed by analyzing caspase- 3 cleavage (Figure $7 f$ and Supplementary Figure 8C).

Crosstalk between WFS1 and AATF signaling pathways mediates a self-perpetuating cycle of cell death in WFS1deficient cells. We compared gene expression profiles of WFS1-knockdown and AATF-knockdown cells, followed by treatment with thapsigargin. Of particular interest are genes, the expression profiles of which are the same in both WFS1knockdown and AATF-knockdown cells. The expression of 
a

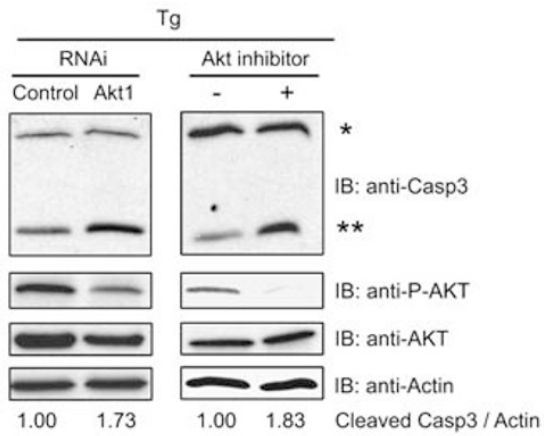

C

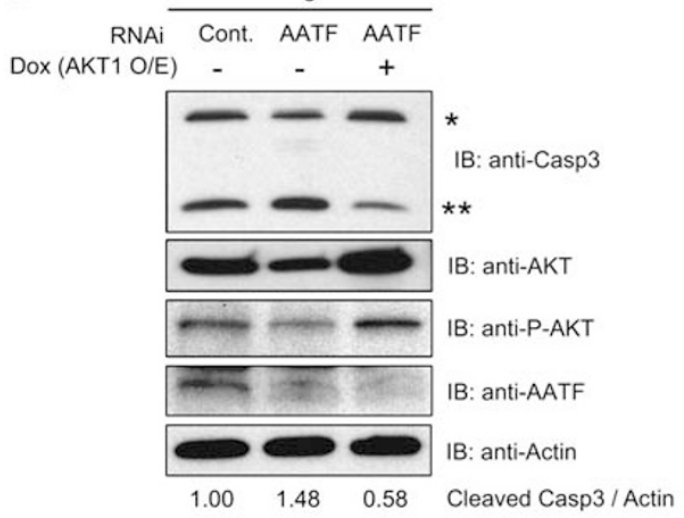

e

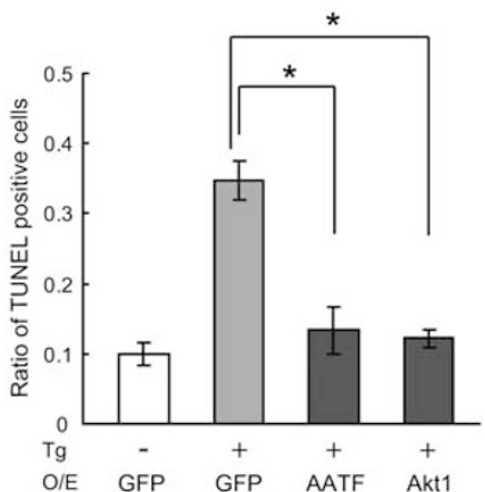

b

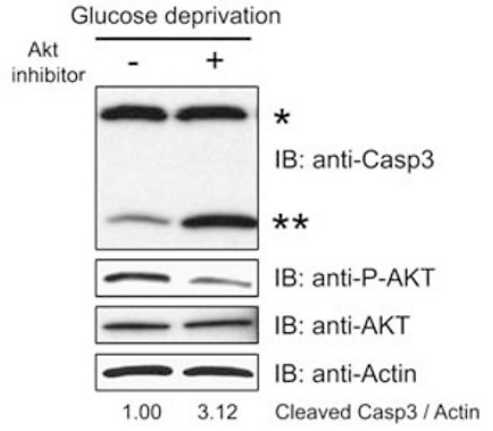

d

RNAi cont. cont. Akt1

Dox (AATF O/E) - + +

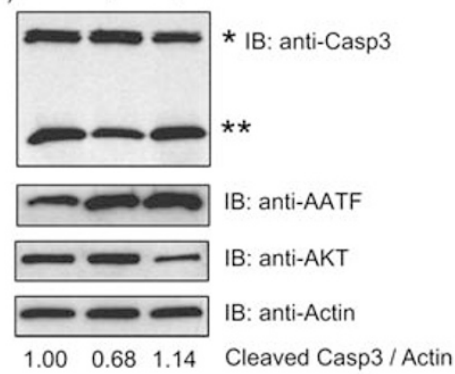

f

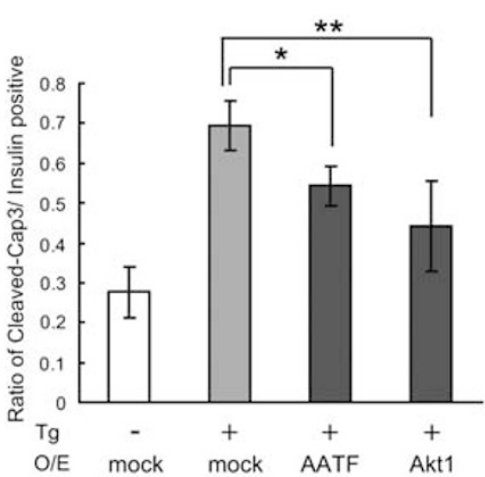

Figure 7 The AATF-AKT1 pathway protects cells from ER stress-mediated apoptosis. (a) INS-1 832/13 cells were transfected with control scrambled siRNA or siRNA against Akt1, then treated with $0.5 \mu \mathrm{M}$ of thapsigargin (Tg) for $16 \mathrm{~h}$ (left panel). INS-1 832/13 cells were pretreated overnight with $10 \mathrm{nM}$ of Akt inhibitor (SH-5) or an equivalent amount of DMSO (control), then treated with $0.25 \mu \mathrm{M}$ of thapsigargin (Tg) for $16 \mathrm{~h}$ (right panel). Expression levels of caspase-3 (Casp3), phosphorylated AKT (P-AKT), total AKT (AKT), and actin were measured by immunoblot. Single and double asterisks indicate uncleaved and cleaved caspase-3, respectively. The ratio between cleaved caspase-3 and actin was measured using ImageJ software. (b) INS-1 832/13 cells were pretreated with $10 \mathrm{nM}$ of Akt inhibitor (SH-5) or an equivalent amount of DMSO overnight, then cultured in glucose-free media for $48 \mathrm{~h}$. Expression levels of caspase-3 (Casp3), phosphorylated AKT (P-AKT), total AKT (AKT), and actin were measured by immunoblot. Single and double asterisks indicate uncleaved and cleaved caspase-3, respectively. The ratio between cleaved caspase-3 and actin was measured using ImageJ software. (c) INS-1 832/13 cells were stably transduced with LV-TO/Akt1, an inducible lentivirus expressing the active form of Akt1. Cells were cultured with or without doxycycline $(4 \mathrm{ng} / \mathrm{ml})$ to induce Akt1 for $48 \mathrm{~h}$, then challenged with thapsigargin $(\mathrm{Tg}, 0.5 \mu \mathrm{M})$ for $16 \mathrm{~h}$. Cells were also transfected with control scrambled siRNA (Cont) or siRNA against AATF. Expression levels of caspase-3 (Casp3), total AKT (AKT), phosphorylated AKT (P-AKT), AATF, and actin were measured by immunoblot. Single and double asterisks indicate uncleaved and cleaved caspase-3, respectively. The ratio between cleaved caspase-3 and actin was measured using ImageJ software. (d) INS-1 832/13 cells were stably transduced with LV-TO/AATF, an inducible lentivirus expressing AATF. Cells were cultured with or without doxycycline $(2 \mu \mathrm{g} / \mathrm{ml})$ to induce AATF for $48 \mathrm{~h}$, then challenged with thapsigargin $(\mathrm{Tg}, 0.5 \mu \mathrm{M})$ for $16 \mathrm{~h}$. Cells were also transfected with control scrambled siRNA (Cont) or siRNA against Akt1. Expression levels of caspase-3 (Casp3), AATF, total AKT (AKT), and actin were measured by immunoblot. Single and double asterisks indicate uncleaved and cleaved caspase-3, respectively. The ratio between cleaved caspase-3 and actin was measured using ImageJ software. (e) Mouse primary islets were infected with LV-TO/AATF (AATF), LV-TO/Akt1 (Akt1), and LV-TO/ GFP (GFP), lentiviruses expressing AATF, active form of Akt1, and GFP, respectively. GFP signals were positive in all viable islets at 2 days after infection (Supplementary Figure 7A). Islets were then treated with thapsigargin $(\mathrm{Tg}, 0.5 \mu \mathrm{M})$ for $6 \mathrm{~h}$. Apoptotic cells were detected by TUNEL staining $(n=4$; values are mean \pm S.D.). Statistics were performed by one-way ANOVA. ${ }^{*} P<0.01$ denotes significant differences between cells infected with GFP and AATF or Akt1. (f) Mouse primary islets were infected with LVTO/AATF (AATF), LV-TO/Akt1 (Akt1), and empty LV-TO (mock) virus. Islets were then treated with thapsigargin (Tg, $0.5 \mu \mathrm{M}$ ) for $6 \mathrm{~h}$. After dispersion, cells were fixed and stained with anti-cleaved caspase-3 and anti-insulin antibodies as shown in Supplementary Figure 7C. The ratio of cells with cleaved-caspase-3 signals to those with insulin signals was calculated ( $n=4$; values are mean \pm S.D.). Statistics were performed by one-way ANOVA. ${ }^{*} P<0.05$ and ${ }^{\star *} P<0.01$ denote significant differences between cells infected with mock AATF or mock Akt1, respectively 
five probes (four known genes and one unknown locus) decreased in both WFS1-knockdown and AATF-knockdown cells (Supplementary Table 3). Expression of 46 probes decreased in AATF-knockdown cells and expression of 276 probes decreased in WFS1-knockdown cells, compared with control cells transfected with scrambled siRNA. Thus, the probability of having five common probes decrease in both WFS1-knockdown and AATF-knockdown cells is 3.22e-06, using a hypergeometric test. Expression of two known genes increased in both WFS1-knockdown and AATF-knockdown cells (Supplementary Table 3). Expression of 33 genes increased in AATF-knockdown cells and expression of 22 genes increased in WFS1-knockdown cells, compared with control cells transfected with scrambled siRNA. Thus, the probability of having two common probes increase in both WFS1-knockdown and AATF-knockdown cells is 6.91e-08. These results raised the possibility that there exists substantial crosstalk between WFS1 and AATF signaling pathways.

To confirm this possibility, we measured Akt1 gene expression in WFS1-knockdown cells and control cells treated with thapsigargin. As predicted, Akt1 gene expression was decreased in WFS1-knockdown cells as compared with control cells (Supplementary Figure 9A). We could restore Akt1 gene expression by introducing AATF in WFS1-knockdown cells (Supplementary Figure 9B).

Gene expression profiling revealed that expression of WFS1 was decreased in AATF-knockdown cells (Supplementary Table 3). Quantitative real-time PCR and immunoblot confirmed this result (Supplementary Figure 9C). It has been shown that XBP-1 is important in activating the WFS1 promoter. ${ }^{29,30}$ We therefore considered the possibility that the addition of AATF expression to XBP-1 expression can enhance WFS1 promoter activity. To test this idea, we cotransfected WFS1-promoter reporter plasmid and the active form of XBP-1 expression plasmid with or without AATF expression plasmid into neuro2a cells. As predicted, the addition of AATF expression plasmid enhanced the induction of luciferase activity (Supplementary Figure 9D). Collectively, these results indicate that there exists substantial positive crosstalk between the WFS1 and AATF signaling pathways and lack of WFS1 mediates a self-perpetuating cycle of cell death (Figure 8).

\section{Discussion}

Through the gene expression profiling of $\beta$-cells lacking WFS1, we discovered a novel antiapoptotic gene of the UPR, AATF. On the basis of the results of this study, we propose the following model for the antiapoptotic activities elicited by AATF in response to ER stress (Figure 8). We found that AATF is induced by PERK signaling and transcriptionally activates the Akt1 gene with Stat3, which confers on cells resistance to ER stress. We also found that there exists a positive crosstalk between AATF and WFS1 signaling pathways, and that WFS1-deficiency or AATF-deficiency mediates a self-perpetuating cycle of cell death.

Previous studies have shown that UPR activates death pathways under ER stress conditions. ${ }^{4-7}$ However, the characterization of antiapoptotic activities in the UPR is

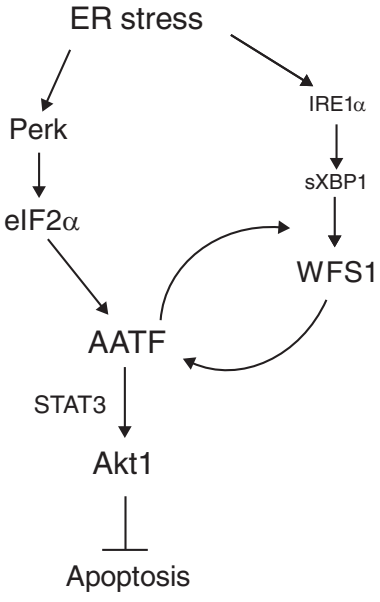

Figure 8 The AATF-Akt1 pathway protects cells from ER stress-mediated apoptosis. Proposed pathway that protects cells from ER stress-mediated cell death

currently incomplete. ${ }^{4}$ Our discovery of antiapoptotic programs regulated by AATF provides evidence that the UPR directly activates both survival and death pathways. During physiological ER stress induction, survival pathway activation outweighs death pathway activation, whereas during chronic unresolvable ER stress conditions, death pathway activation dominates that of survival pathways. The mechanisms of this switch from physiology to pathology may be regulated by AATF expression.

Apoptosis antagonizing transcription factor has been shown to have a function in DNA damage response, in which AATF promotes cell proliferation by regulating transcription of prosurvival factors such as p53 and XIAP. ${ }^{31,32}$ We identified Akt1 as an AATF-targeted gene that protects cells from ER stress-mediated cell death. We found that AATF induces Akt1, together with Stat3, under ER stress conditions. On the basis of our findings and those of previous studies, ${ }^{31,32}$ we propose that AATF functions as a transcription cofactor regulating prosurvival genes on certain cellular stress conditions.

Puma and Bim, members of $\mathrm{BH}-3$ proteins, have been implicated in contributing to apoptotic signaling downstream of ER stress. ${ }^{33,34}$ Akt has been shown to be involved in regulating both Puma and Bim in certain cell types, ${ }^{35,36}$ raising the possibility that Puma and Bim expression is regulated by AATF or WFS1. However, Puma or Bim expression was not affected in INS-1 832/13 cells transfected with siRNA directed against WFS1 or AATF (Supplementary Figure 10), indicating that AATF-Akt1 signaling is not involved in the regulation of Puma and Bim.

Akt activation and the following signaling cascade have been shown to be involved in ER stress-mediated apoptosis in various cells including pancreatic $\beta$-cells. ${ }^{25,26}$ Most of the reports emphasized that the state of AKT phosphorylation regulates its survival function. It is possible that increasing AKT1 by itself may not increase survival. Nevertheless, increased AKT1 could contribute to survival signaling mediated by another agent induced by ER stress that increases AKT1 phosphorylation. We clearly showed that 
AATF depletion diminished not only Akt1 gene expression but also AKT phosphorylation in $\beta$-cells, indicating that transcriptional regulation of Akt1 gene is also important for sustaining its functional activity. Further studies will be required to completely understand the mechanisms by which Akt1 protects cells from ER stress-mediated apoptosis.

We have found that there is crosstalk between the WFS1 and AATF signaling pathways. Because WFS1-deficiency attenuates AATF-Akt1 signaling and causes cell death, a self-perpetuating cycle of cell death might be involved in the progression of $\beta$-cell death in Wolfram syndrome.

Increasing evidence indicates that chronic ER stress has a role in the pathogenesis of various diseases including diabetes mellitus. ${ }^{37-39}$ Chronic unresolvable ER stress leads to cellular dysfunction and the activation of cell death pathways. Therefore, a more precise understanding of the antiapoptotic programs in the UPR may lead to the development of new treatments for diseases caused by chronic ER stress. Thus, the cell signaling pathway regulated by the AATF-Akt1 pathway may be a useful target for the treatment of diseases caused by ER stress-mediated cell death.

\begin{abstract}
Materials and Methods
Cell culture and transfection of siRNA. Rat insulinoma cells, INS-1 832/ 13 , were a gift from Dr. Christopher Newgard (Duke University Medical Center). These cells were cultured in RPMI 1640 supplemented with 10\% FBS. Mouse embryonic fibroblasts and neuro2a cells were maintained in DMEM with $10 \%$ fetal bovine serum. Ire $1 \alpha^{-1-}$ and Perk ${ }^{-1-}$ fibroblasts were a gift from Dr. David Ron (New York University School of Medicine).

The Nucleofector Device (Amaxa Biosystems, Gaithersburg, MD, USA) was used to transfect siRNA directed against WFS1, AATF, and Akt1 into INS-1 832/13 cells. At Qiagen (Valencia, CA, USA), siRNAs directed against rat WFS1, AATF, and Akt1 were designed and synthesized: rat WFS1, AAGGCATGAAGGTCTAC AATT; for rat AATF, AAGCGCTCTGCCTACCGAGTT; and for rat Akt1, AACGCCTGAGGAGCGGGAAGA. Cells were incubated in media overnight after siRNA transfection and then additional treatments were performed, including ER stress induction. For plasmid transfection into neuro2a cells, we used Lipofectamine 2000 (Invitrogen, Carlsbad, CA, USA), and for plasmid transfection into mouse embryonic fibroblasts, we used the Nucleofector Device (Amaxa Biosystems).
\end{abstract}

GeneChip array analysis. INS-1 832/13 cells were transfected with siRNA against WFS1 or AATF, as well as against control scrambled siRNA. Cells were incubated overnight, and then treated with $1.0 \mu \mathrm{M}$ of thapsigargin for $8 \mathrm{~h}$. Total RNA was isolated for each sample and processed for GeneChip analysis by the Whitehead Institute Center for microarray technology (Cambridge, MA, USA). The final product was hybridized to GeneChip Rat Genome 2302.0 Arrays (Affymetrix, Santa Clara, CA, USA) and scanned with a GeneChip Scanner 3000.

The RMA method ${ }^{40,41}$ in Affy package from Bioconductor was used in $\mathrm{R}$ to summarize the probe level data and normalize the data set to remove variation across the array. Log-transformed data were used in the subsequent analysis. Samples treated with siRNA against WFS1 or AATF $(n=3$, for each RNAi treatment) were compared with control sample $(n=3)$. The Limma package from Bioconductor $^{42}$ with randomized block design was used to determine whether a gene's expression level differs between treatments. Genes with an adjusted $P$-value $<0.01^{43}$ was considered to be significant.

Lentivirus system. Mouse AATF and mouse Akt1 cDNAs were purchased from Open Biosystems, and their cds portions were subcloned into lentiviral expression vectors ( $p L e n t i-C M V / T O$, kind gifts from Dr. Eric Campeau at University of Massachusetts Medical School). Lentiviral particles were produced in HEK293T cells by transfection using Lipofectamine 2000 (Invitrogen). Lentiviral-containing supernatant was collected $48 \mathrm{~h}$ after transfection, and stored at $-80^{\circ} \mathrm{C}$. Details of this lentivirus system were described previously. ${ }^{4}{ }^{4}$
Immunoblotting and immunoprecipitation. Cells were lysed in M-PER buffer (PIERCE, Rockford, IL, USA) containing protease inhibitors for $15 \mathrm{~min}$ on ice. The lysates were then cleared by centrifuging cells at $13000 \times g$ for $15 \mathrm{~min}$ at $4^{\circ} \mathrm{C}$. Lysates were normalized for total protein (30 $\mu$ g per lane), separated using a $4-20 \%$ linear gradient SDS-PAGE (BioRad, Hercules, CA, USA), and electroblotted. Blots were probed with the following antibodies: anti-human AATF (Bethyl, Montgomery, TX, USA); anti-mouse and rat AATF antibody, generated using a peptide, RPREADPEADPEEATR; anti-actin (Sigma, St. Louis, MO, USA); anti-eIF2 $\alpha$ (Santa Cruz Biotechnology, Santa Cruz, CA, USA); anti-phospho-elF2 $\alpha$, anti-Akt, anti-Akt1, anti-phospho-Akt, anti-Creb, anti-tubulin, and anti-caspase-3 (Cell Signaling, Danvers, MA, USA). When immunoprecipitated, cells were lysed in a nuclear lysis buffer ( $50 \mathrm{mM}$ Tris- $\mathrm{HCl}, \mathrm{pH} 7.5,5 \mathrm{mM} \mathrm{MgCl}, 200 \mathrm{mM} \mathrm{KCl}, 0.5 \mathrm{mM}$ EDTA, $1 \mathrm{mM}$ dithiothreitol, $50 \mathrm{mM} \mathrm{NaF}, 1 \mathrm{mM} \beta$-glycerophosphate, $0.5 \% \mathrm{NP}-40$ ). Nuclear lysates were incubated with $200 \mu \mathrm{g} / \mathrm{ml}$ DNase I and $10 \mu \mathrm{g} / \mathrm{ml}$ RNase A for $30 \mathrm{~min}$ at $26^{\circ} \mathrm{C}$. After centrifugation at $10000 \times \mathrm{g}$ for $10 \mathrm{~min}$ at $4^{\circ} \mathrm{C}$, supernatants were precleared with protein G-Sepharose (GE Healthcare Bio-Sciences, Uppsala, Sweden), an anti-AATF antibody (Bethyl) was then added, and cells were incubated at $4^{\circ} \mathrm{C}$ with rotation. Immune complexes were then incubated overnight with protein G-Sepharose, collected by centrifugation, and washed four times with the lysis buffer.

Real-time polymerase chain reaction. Total RNA was isolated from cells using the RNeasy Mini Kit (Qiagen) and reverse transcribed using $1 \mu \mathrm{g}$ of total RNA from cells with Oligo-dT primer. For the thermal cycle reaction, the iQ5 system (BioRad) was used at $95^{\circ} \mathrm{C}$ for $10 \mathrm{~min}$, followed by 40 cycles at $95^{\circ} \mathrm{C}$ for $10 \mathrm{~s}$ and $55^{\circ} \mathrm{C}$ for $30 \mathrm{~s}$.

The relative amount of each transcript was calculated by a standard curve of cycle thresholds for serial dilutions of CDNA samples and normalized to the amount of $\beta$-actin. Polymerase chain reaction (PCR) was performed in triplicate for each sample, after which all experiments were repeated twice. The following sets of primers and Power SYBR Green PCR Master Mix (Applied Biosystems, Foster City, CA, USA) were used for real-time PCR: for mouse AATF, TTCTTGGCAAACCGGA GC and AGCGTCTCTGGTTCTCCTGG; for mouse actin, GCAAGTGCTTCTAGGC GGAC and AAGAAAGGGTGTAAAACGCAGC; for mouse Akt1, ATGGACTCAAGA GGCAGGAA and TCTTCAGCCCCTGAGTTGTC; for rat AATF, CCGAGTTCTTG GCAAACCTG and TCTCCGGTTCTCCTGGCA; for rat actin, GCAAATGCTTCTA GGCGGAC and AAGAAAGGGTGTAAAACGCAGC; for rat BiP, TGGGTACATTTG ATCTGACTGGA and CTCAAAGGTGACTTCAATCTGGG; for rat Akt1, ACCACCG CCATTCAGACTG and TTGTCACTGGGTGAACCTGA; for rat Chop, AGAGTGGT CAGTGCGCAGC and CTCATTCTCCTGCTCCTTCTCC; for rat total XBP-1, TGGCCGGGTCTGCTGAGTCCG and ATCCATGGGAAGATGTTCTGG; for ratspliced XBP-1, CTGAGTCCGAATCAGGTGCAG (the original CAG sequence was mutated to $A A T$ to reduce the background signal from unspliced XBP-1) and ATCCATGGGAAGATGTTCTGG; for rat WFS1, ATCGACAACAGCGCCGA and GCATCCAGTCACCCAGGAAG.

TUNEL assay. Apoptotic cell death was assessed by the TUNEL assay. We counted apoptotic cells using the DeadEnd Colorimetric TUNEL System (Promega, Madison, WI, USA). Counting was carried out by an investigator who was blind to the experimental condition.

Promoter assay. The intron1 promoter region of the mouse Akt1 gene was amplified by PCR and cloned into the Kpnl/Xhol site of the pGL4.14 vector (Promega). pFlag-STAT3-C vector expressing the constitutive form of STAT3 was obtained from addgene (Addgene, Cambridge, MA, USA). ${ }^{45}$ Neuro2a cells were transfected with pGL4.14/Akt1 ${ }^{-1323 /-32}$, pFlag/STAT3-C (STAT3), pCS2 + /AATF (AATF), siRNA directed against AATF, and pcDNA3/ $\beta$-galactosidase. pGL4.14 and control scrambled siRNA were used as negative controls. At $24 \mathrm{~h}$ after transfection, lysates were prepared using a Luciferase Assay System kit (Promega). The light produced from samples was read by a standard plate reading luminometer. $\beta$-galactosidase activity was measured by $\beta$-Gal Reporter Gene Assay, chemiluminescent (Roche Diagnostics, Mannheim, Germany). The assay was performed independently three times.

Chromatin immunoprecipitation. HEK293T cells were transfected with pFlag-STAT3-C with or without pCS2 + /AATF. Cells were fixed after $24 \mathrm{~h}$ of incubation. ChIPs were performed as previously described. ${ }^{46}$ Purified DNA from crosslinked cells was dissolved in $50 \mu \mathrm{l} \mathrm{TE;} 3 \mu \mathrm{l}$ was used for PCR. Inputs consisted of $1 \%$ chromatin before immunoprecipitation. Quantitative PCRs were performed as 
described in the Real-time polymerase chain reaction section using the following primer sets: for mouse Akt1 promoter (intron1), TCCCTCTGGAAGAGAAGCAA and TAGCTAGCCTGTGCAAAGCA; for mouse Akt1 cds (exon3), ATGGACTCAAGA GGCAGGAA and TCTTCAGCCCCTGAGTTGTC.

Primary islet culture. Mouse primary islets were taken from C57BL/6 mice. Mice were anesthetized, and their pancreatic islets were isolated by pancreatic duct injection of $5 \mathrm{ml}(0.85 \mathrm{mg} / \mathrm{ml})$ of collagenase solution, followed by digestion at $37^{\circ} \mathrm{C}$ for 25 min with mild shaking. Digestion was stopped by adding ice-cold RPMI with $1 \%$ horse serum. Islets were washed several times with RPMI, separated from acinar cells on a Histopaque gradient, and handpicked using a dissecting microscope. Islets were infected with $1.0 \times 10^{6} \mathrm{TU} / \mathrm{ml}$ of lentiviruses expressing mouse AATF, mouse Akt1, and GFP. After $4 \mathrm{~h}$ of infection, the media were changed, and then incubated for $24 \mathrm{~h}$. Islets were then challenged with $0.5 \mu \mathrm{M}$ thapsigargin for $6 \mathrm{~h}$. They were collected by centrifugation and treated with trypsin and DNAse at $37^{\circ} \mathrm{C}$ for $15 \mathrm{~min}$ to be dispersed into single cells, followed by TUNEL staining or immunohistochemistry. For immunohistochemistry, we used anti-cleaved-caspase3 antibody (Cell Signaling) and anti-insulin antibody (Dako, Carpinteria, CA, USA).

Statistical analysis. Cell death (y) was measured as a proportion of dead cells among all cells treated. Frequently arcsine (sqrt(y)) transformation is applied to raw data to homogenize the variance before further data analysis. ${ }^{47}$ Therefore, all analyses involving cell death data were performed on transformed data.

Two-way ANOVA was performed to determine the main effect of WFS1 RNAi, the main effect of thapsigargin, and the interaction between WFS1 RNAi and thapsigargin (Figure 1b). In addition, a set of predetermined contrasts were performed. Two-way ANOVA was also performed in the same way as in Figure $4 \mathrm{~b}$ and c. One-way ANOVA was performed to determine whether there is any difference among four treatment groups (Figures $7 \mathrm{e}$ and f). In addition, a set of predetermined contrasts were performed.

\section{Conflict of interest}

The authors declare no conflict of interest.

Acknowledgements. We thank $\mathrm{E}$ Campeau for providing lentiviral expression systems; MR Green, KL Lipson, C Kakiuchi, R Ghosh, and Y Okawa for helpful discussions; $\mathrm{K}$ Sargent and $\mathrm{L}$ Leehy for technical assistance. Research in the laboratory of F Urano was supported by an NIH R01DK067493 grant, a grant from the Diabetes and Endocrinology Research Center at the University of Massachusetts Medical School (DK032520), a Juvenile Diabetes Research Foundation Regular Grant, and an lacocca Foundation/Juvenile Diabetes Research Foundation joint grant.

1. Ron D, Walter $P$. Signal integration in the endoplasmic reticulum unfolded protein response. Nat Rev Mol Cell Biol 2007; 8: 519-529.

2. Rutkowski DT, Kaufman RJ. That which does not kill me makes me stronger: adapting to chronic ER stress. Trends Biochem Sci 2007; 32: 469-476.

3. Szegezdi E, Logue SE, Gorman AM, Samali A. Mediators of endoplasmic reticulum stress-induced apoptosis. EMBO Rep 2006; 7: 880-885.

4. Kim I, Xu W, Reed JC. Cell death and endoplasmic reticulum stress: disease relevance and therapeutic opportunities. Nat Rev 2008; 7: 1013-1030.

5. Zinszner H, Kuroda M, Wang X, Batchvarova N, Lightfoot RT, Remotti $\mathrm{H}$ et al. CHOP is implicated in programmed cell death in response to impaired function of the endoplasmic reticulum. Genes Dev 1998; 12: 982-995.

6. Urano F, Wang X, Bertolotti A, Zhang Y, Chung P, Harding HP et al. Coupling of stress in the ER to activation of JNK protein kinases by transmembrane protein kinase IRE1. Science 2000; 287: 664-666.

7. Nishitoh H, Matsuzawa A, Tobiume K, Saegusa K, Takeda K, Inoue $\mathrm{K}$ et al. ASK1 is essential for endoplasmic reticulum stress-induced neuronal cell death triggered by expanded polyglutamine repeats. Genes Dev 2002; 16: 1345-1355.

8. Eizirik DL, Cardozo AK, Cnop M. The role for endoplasmic reticulum stress in diabetes mellitus. Endocr Rev 2008; 29: 42-61.

9. Fonseca SG, Lipson KL, Urano F. Endoplasmic reticulum stress signaling in pancreatic beta-cells. Antioxid Redox Signal 2007; 9: 2335-2344.

10. Riggs AC, Bernal-Mizrachi E, Ohsugi M, Wasson J, Fatrai S, Welling $C$ et al. Mice conditionally lacking the Wolfram gene in pancreatic islet beta cells exhibit diabetes as a result of enhanced endoplasmic reticulum stress and apoptosis. Diabetologia 2005; 48 . 2313-2321.
11. Yamada T, Ishihara H, Tamura A, Takahashi R, Yamaguchi S, Takei D et al. WFS1deficiency increases endoplasmic reticulum stress, impairs cell cycle progression and triggers the apoptotic pathway specifically in pancreatic beta-cells. Hum Mol Genet 2006; 15: $1600-1609$.

12. Karasik A, O'Hara C, Srikanta S, Swift M, Soeldner JS, Kahn CR et al. Genetically programmed selective islet beta-cell loss in diabetic subjects with Wolfram's syndrome. Diabetes Care 1989; 12: 135-138

13. Inoue $\mathrm{H}$, Tanizawa $\mathrm{Y}$, Wasson J, Behn $\mathrm{P}$, Kalidas $\mathrm{K}$, Bernal-Mizrachi $\mathrm{E}$ et al. A gene encoding a transmembrane protein is mutated in patients with diabetes mellitus and optic atrophy (Wolfram syndrome). Nat Genet 1998; 20: 143-148.

14. Strom TM, Hortnagel K, Hofmann S, Gekeler F, Scharfe C, Rabl W et al. Diabetes insipidus, diabetes mellitus, optic atrophy and deafness (DIDMOAD) caused by mutations in a novel gene (wolframin) coding for a predicted transmembrane protein. Hum Mol Genet 1998; 7: 2021-2028.

15. Fonseca SG, Fukuma M, Lipson KL, Nguyen LX, Allen JR, Oka Y et al. WFS1 is a novel component of the unfolded protein response and maintains homeostasis of the endoplasmic reticulum in pancreatic \{beta\}-cells. J Biol Chem 2005; 280: 39609-39615.

16. Page G, Lodige I, Kogel D, Scheidtmann KH. AATF, a novel transcription factor that interacts with DIk/ZIP kinase and interferes with apoptosis. FEBS Lett 1999; 462 : 187-191.

17. Bruno $T$, De Angelis R, De Nicola F, Barbato C, Di Padova M, Corbi N et al. Che-1 affects cell growth by interfering with the recruitment of HDAC1 by Rb. Cancer Cell 2002; 2: 387-399.

18. Fanciulli M, Bruno T, Di Padova M, De Angelis R, lezzi S, lacobini $C$ et al. Identification of a novel partner of RNA polymerase II subunit 11, Che-1, which interacts with and affects the growth suppression function of $\mathrm{Rb}$. FASEB J 2000; 14: 904-912.

19. Harding HP, Novoa I, Zhang Y, Zeng H, Wek R, Schapira M et al. Regulated translation initiation controls stress-induced gene expression in mammalian cells. Mol Cell 2000; 6 : 1099-1108.

20. Harding HP, Zhang Y, Ron D. Protein translation and folding are coupled by an endoplasmic-reticulum-resident kinase. Nature 1999; 397: 271-274.

21. Boyce M, Bryant KF, Jousse C, Long K, Harding HP, Scheuner D et al. A selective inhibitor of elF2alpha dephosphorylation protects cells from ER stress. Science 2005; 307 : 935-939.

22. Kozutsumi Y, Segal M, Normington K, Gething MJ, Sambrook J. The presence of malfolded proteins in the endoplasmic reticulum signals the induction of glucose-regulated proteins. Nature 1988; 332: 462-464.

23. Franke TF. PI3K/Akt: getting it right matters. Oncogene 2008; 27: 6473-6488.

24. Amaravadi R, Thompson CB. The survival kinases Akt and Pim as potential pharmacological targets. J Clin Invest 2005; 115: 2618-2624.

25. Srinivasan S, Ohsugi M, Liu Z, Fatrai S, Bernal-Mizrachi E, Permutt MA. Endoplasmic reticulum stress-induced apoptosis is partly mediated by reduced insulin signaling through phosphatidylinositol 3-kinase/Akt and increased glycogen synthase kinase-3beta in mouse insulinoma cells. Diabetes 2005; 54: 968-975.

26. Hu P, Han Z, Couvillon AD, Exton JH. Critical role of endogenous Akt/IAPs and MEK1/ERK pathways in counteracting endoplasmic reticulum stress-induced cell death. J Biol Chem 2004; 279: 49420-49429.

27. Park S, Kim D, Kaneko S, Szewczyk KM, Nicosia SV, Yu H et al. Molecular cloning and characterization of the human AKT1 promoter uncovers its up-regulation by the Src/Stat3 pathway. J Biol Chem 2005; 280: 38932-38941.

28. Xu Q, Briggs J, Park S, Niu G, Kortylewski M, Zhang S et al. Targeting Stat3 blocks both HIF-1 and VEGF expression induced by multiple oncogenic growth signaling pathways. Oncogene 2005; 24: 5552-5560.

29. Kakiuchi C, Ishigaki S, Oslowski CM, Fonseca SG, Kato T, Urano F. Valproate, a mood stabilizer, induces WFS1 expression and modulates its interaction with ER stress protein GRP94. PLOS ONE 2009; 4: e4134.

30. Kakiuchi C, Ishiwata M, Hayashi A, Kato T. XBP1 induces WFS1 through an endoplasmic reticulum stress response element-like motif in SH-SY5Y cells. J Neurochem 2006; 97 : 545-555.

31. Bruno $T$, De Nicola $F$, lezzi $S$, Lecis D, D'Angelo $C$, Di Padova $M$ et al. Che-1 phosphorylation by ATM/ATR and Chk2 kinases activates p53 transcription and the G2/M checkpoint. Cancer Cell 2006; 10: 473-486.

32. Bruno T, lezzi S, De Nicola F, Di Padova M, Desantis A, Scarsella M et al. Che-1 activates XIAP expression in response to DNA damage. Cell Death Differ 2008; 15: 515-520.

33. Puthalakath $\mathrm{H}$, O'Reilly LA, Gunn P, Lee L, Kelly PN, Huntington ND et al. ER stress triggers apoptosis by activating BH3-only protein Bim. Cell 2007; 129: 1337-1349.

34. Reimertz C, Kogel D, Rami A, Chittenden T, Prehn JH. Gene expression during ER stressinduced apoptosis in neurons: induction of the $\mathrm{BH} 3$-only protein Bbc3/PUMA and activation of the mitochondrial apoptosis pathway. J Cell Biol 2003; 162: 587-597.

35. Sugatani T, Hruska KA. Akt1/Akt2 and mammalian target of rapamycin/Bim play critical roles in osteoclast differentiation and survival, respectively, whereas Akt is dispensable for cell survival in isolated osteoclast precursors. J Biol Chem 2005; 280 : 3583-3589.

36. Karst AM, Dai DL, Cheng JQ, Li G. Role of p53 up-regulated modulator of apoptosis and phosphorylated Akt in melanoma cell growth, apoptosis, and patient survival. Cancer Res 2006; 66: 9221-9226. 
37. Marciniak SJ, Ron D. Endoplasmic reticulum stress signaling in disease. Physiol Rev 2006; 86: 1133-1149.

38. Yamamoto K, Sato T, Matsui T, Sato M, Okada T, Yoshida H et al. Transcriptional induction of mammalian ER quality control proteins is mediated by single or combined action of ATF6alpha and XBP1. Dev Cell 2007; 13: 365-376.

39. Lipson KL, Fonseca SG, Urano F. Endoplasmic reticulum stress-induced apoptosis and auto-immunity in diabetes. Curr Mol Med 2006; 6: 71-77.

40. Irizarry RA, Hobbs B, Collin F, Beazer-Barclay YD, Antonellis KJ, Scherf $U$ et al. Exploration, normalization, and summaries of high density oligonucleotide array probe level data. Biostatistics 2003; 4: 249-264.

41. Irizarry RA, Bolstad BM, Collin F, Cope LM, Hobbs B, Speed TP. Summaries of Affymetrix GeneChip probe level data. Nucleic Acids Res 2003; 31: e15.
42. Smyth GK. Linear models and empirical bayes methods for assessing differential expression in microarray experiments. Stat Appl Genet Mol Biol 2004; 3: Article3.

43. Benjamini $Y$, Hochberg $Y$. Controlling the false discovery rate: a practical and powerful approach to multiple testing. J R Statist Soc B 1995; 57: 289-300.

44. Campeau E, Ruhl VE, Rodier F, Smith CL, Rahmberg BL, Fuss JO et al. A versatile viral system for expression and depletion of proteins in mammalian cells. PLOS ONE 2009; 4: e6529.

45. Bromberg JF, Wrzeszczynska MH, Devgan G, Zhao Y, Pestell RG, Albanese $C$ et al. Stat3 as an oncogene. Cell 1999; 98: 295-303.

46. Ohkawa Y, Marfella CG, Imbalzano AN. Skeletal muscle specification by myogenin and Mef2D via the SWI/SNF ATPase Brg1. EMBO J 2006; 25: 490-501.

47. Freeman MF, Tukey JW. Transformations related to the angular, and the square root. Ann Mathem Stat 1950; 21: 607-611.

Supplementary Information accompanies the paper on Cell Death and Differentiation website (http://www.nature.com/cdd) 